\title{
Replacement pattern of the pharyngeal teeth in cyprinid fish, Tribolodon hakonensis
}

\author{
Tsuneo Nakajima, Hisaho Yoshida, Banri Sone and Yoshihiko Hotta \\ Department of 2nd Oral Anatomy (Chief: Prof. Kuhei Furuhashi), Gifu College of Dentistry, \\ 1851, Takano, Hozumi-cho, Motosu-gun, Gifu Pref. 501-02
}

[Accepted for publication: June 10, 1983]

Key words: pharyngeal tooth / replacement pattern / cyprinid

Cyprinid fish, lacking teeth on the jaws, have well-developed dentition on the pharyngeal bones. They continue to replace these teeth throughout their life span just the other non-mammalian vertebrates with their jaw teeth. This phenomenon occurs because the small teeth present in the larvae and juveniles are inadequate for the jaws of adults, and because the change of preys as they grow requires morphological changes of the teeth. The pharyngeal teeth are replaced with regularity in cyprinid fish. The tooth germs are initiated in cyclic order, 5-3-1-4-2 in the row bearing five teeth and 3-1-4-2 in the row bearing four teeth, i.e. the teeth are replaced alternately and cephalad ${ }^{1-4)}$. This replacement pattern is the same as that of jaw tooth replacement seen in the other non-mammalian vertebrates.

The authors have undertaken the analyses of pharyngeal teeth in cyprinoids to study the replacement pattern. In the present paper, they will examine the pharyngeal teeth of Japanese dace, Tribolodon hakonensis, which has a double-row and bilaterally asymmetrical dentition.

\section{Materials and Methods}

Specimens of $T$. hakonensis were collected from Lake Biwa in April, 1981. The specimens observed were 36 adults of 23.8-29.6 $\mathrm{mm}$ standard length (SL).

They were fixed in $10 \%$ formalin, cleared in $1 \% \mathrm{KOH}$, and stained with alizarin red $\mathrm{S}$. The pharyngeal arch was taken from the head region together with the mucous membrane. They were immersed in pure glycerine and examined under a stereoscopic microscope.

The replacement succession was determined on the basis of the difference in the developmental stage among tooth germs, which was judged from the size and/or stainability with alizarin red $\mathrm{S}$.

\section{Results and Discussion}

The dental formula of the present species is usually expressed as $0.2 .5-4.2 .0 .{ }^{5)}$ The left pharyngeal arch has five major row teeth and two minor row teeth, the right arch four major row teeth and two minor row teeth; dentition is bilaterally asymmetrical. Of the 36 examined, one had a bliaterally symmetrical dentition, the dental formula of which was represented as 0.2.4.-4.2.0. This one was excluded from the present analysis.

The major row is called the A row and the minor row the $\mathrm{B}$ row. The individual tooth is numbered in order from the anterior to posterior in each row. The tooth germs of the replacement teeth are numbered in the same way as the functioning teeth.

It is well-known that the pharyngeal teeth are replaced in cyclic order, 5-3-1-4-2 in the row bearing five teeth and 3-1-4-2 in the row bearing four teeth ${ }^{1-4)}$. The succession of these cyclic orders occurred with high frequency (Tables 1, 2 and 3). In the present species, the teeth are generally replaced in the order of 5-3-1-4-2 or 3-1-4-2.

There was a difference in the occurrence frequency of the replacement pattern between the right and left major row. The tooth succession of the order, 5-3-1-4-2, on the 
Table 1. Number of tooth germs successions in each row of 35 analyzed cases. Germ successions with an asterisk do not fit the cyclic order, 5-3-1-4-2 or 3-1-42.

\begin{tabular}{|c|c|c|c|}
\hline \multicolumn{2}{|c|}{ Right arch } & \multicolumn{2}{|c|}{ Left $\operatorname{arch}$} \\
\hline Major row & $\begin{array}{l}\text { Minor } \\
\text { row }\end{array}$ & Major row & $\underset{\text { row }}{\text { Manor }}$ \\
\hline $4(1-4-2-3)$ & $1(1)$ & $3(4-2-5)$ & 1 (2) \\
\hline $4(3-1-4-2)$ & $2(2-1)$ & $3(4-2-5)$ & $1(1)$ \\
\hline $4(3-1-4-2)$ & 0 & $4(3-4-1-2)^{*}$ & $1(2)$ \\
\hline $4(3-1-4-2)$ & $1(2)$ & $4(3-4-2-5)^{*}$ & $1(2)$ \\
\hline $2(4-2)$ & 0 & $3(2-5-3)$ & 0 \\
\hline $3(2-3-1)$ & $1(2)$ & $3(2-3-1) *$ & 0 \\
\hline $3(2-3-1)$ & 0 & $2(3-1)$ & 0 \\
\hline $2(2-3)$ & $1(1)$ & $2(5-3)$ & 0 \\
\hline $2(2-1)^{*}$ & $1(1)$ & $4(2-1-3-5)^{*}$ & 0 \\
\hline $4(3-1-4-2)$ & $1(1)$ & $3(4-2-5)$ & 0 \\
\hline $4(3-1-4-2)$ & $1(2)$ & $3(4-2-5)$ & 1 (1) \\
\hline $2(3-1)$ & $1(2)$ & $4(3-5-4-2) *$ & 0 \\
\hline $3(2-3-1)$ & $1(1)$ & $2(3-1)$ & 0 \\
\hline $4(1-4-2-3)$ & 0 & $3(2-5-3)$ & $1(2)$ \\
\hline $4(3-1-4-2)$ & $1(1)$ & $2(4-2)$ & 0 \\
\hline $2(3-1)$ & $1(1)$ & $4(3-1-4-2)$ & $1(2)$ \\
\hline $2(4-2)$ & 0 & $4(2-5-3-1)$ & 0 \\
\hline $3(2-3-1)$ & 0 & $3(1-4-2)$ & 0 \\
\hline $3(3-1-4)$ & 0 & $3(3-1-4)$ & 0 \\
\hline $2(4-2)$ & 0 & $3(4-2-1)^{*}$ & 0 \\
\hline $2(4-2)$ & 0 & $4(4-2-5-1) *$ & 0 \\
\hline $3(3-1-4)$ & 0 & $4(3-1-4-2)$ & $1(1)$ \\
\hline $3(2-3-1)$ & 0 & $4(2-5-3-1)$ & 0 \\
\hline $3(1-4-2)$ & $1(2)$ & $3(4-2-5)$ & 0 \\
\hline $4(2-3-1-4)$ & $1(2)$ & $4(3-1-4-2)$ & 0 \\
\hline $4(3-1-4-2)$ & 0 & $4(4-2-5-1)^{*}$ & 0 \\
\hline $4(4-1-2-3)$ & 0 & $3(2-3-1)$ & 0 \\
\hline $3(3-1-4)$ & 0 & $3(3-1-4)$ & $1(2)$ \\
\hline $4(3-1-4-2)$ & 0 & $4(4-2-5-1)^{*}$ & 0 \\
\hline $4(2-3-1-4)$ & $1(2)$ & $4(3-1-4-2)$ & 0 \\
\hline $3(3-1-4)$ & 0 & $4(3-1-4-2)$ & 0 \\
\hline $2(4-2)$ & $1(1)$ & $4(4-2-5-3)$ & 0 \\
\hline $3(3-1-4)$ & 0 & $4(3-1-4-2)$ & 0 \\
\hline $4(3-1-4-2)$ & $1(1)$ & $3(4-2-5)$ & $1(2)$ \\
\hline $4(3-1-4-2)$ & $1(1)$ & $3(4-2-5)$ & 0 \\
\hline
\end{tabular}

left arch took place less frequency than that of the order, 3-1-4-2, on the right arch: it occurred with a frequency of $74.3 \%$ on the left major row and with a frequency of
Table 2. Frequency distribution of tooth germ successions in major rows of 35 right arches

\begin{tabular}{ccc}
\hline $\begin{array}{c}\text { No. of tooth } \\
\text { germs }\end{array}$ & $\begin{array}{c}\text { Germ } \\
\text { succession }\end{array}$ & No. of arches \\
\hline $\begin{array}{c}\text { Regarded as a part } \\
\text { of full succession }\end{array}$ & $4-2-3-1$ & $34(97.1 \%)$ \\
4 & $3-1-4-2$ & 10 \\
& $2-3-1-4$ & 3 \\
& $1-4-2-3$ & 2 \\
& $4-1-2-3$ & 1 \\
3 & $2-3-1$ & 6 \\
& $3-1-4$ & 4 \\
2 & $1-4-2$ & 1 \\
& $4-2$ & 5 \\
& $3-1$ & 2 \\
& $2-3$ & 1 \\
Other & & $1(2.9 \%)$ \\
\hline
\end{tabular}

Table 3. Frequency distribution of tooth germ successions in major rows of 35 left arches

\begin{tabular}{|c|c|c|}
\hline $\begin{array}{l}\text { No. of tooth } \\
\text { germs }\end{array}$ & $\begin{array}{l}\text { Germ } \\
\text { succession }\end{array}$ & No. of arches \\
\hline \multicolumn{3}{|c|}{$\begin{array}{l}\text { Regarded as a part } \\
\text { of full succession } 5-3-1-4-2\end{array}$} \\
\hline \multirow[t]{3}{*}{4} & $3-1-4-2$ & 6 \\
\hline & $2-5-3-1$ & 3 \\
\hline & $4-2-5-3$ & 1 \\
\hline \multirow[t]{4}{*}{3} & $4-2-5$ & 7 \\
\hline & $2-5-3$ & 2 \\
\hline & $3-1-4$ & 2 \\
\hline & $1-4-2$ & 1 \\
\hline \multirow[t]{3}{*}{2} & $3-1$ & 2 \\
\hline & $5-3$ & 1 \\
\hline & $4-2$ & 1 \\
\hline Others & & $9(25.7 \%)$ \\
\hline \multirow[t]{5}{*}{4} & $4-2-5-1$ & 3 \\
\hline & $3-4-2-1$ & 1 \\
\hline & $3-4-2-5$ & 1 \\
\hline & $2-1-3-5$ & 1 \\
\hline & $3-5-4-2$ & 1 \\
\hline \multirow[t]{2}{*}{3} & $2-3-1$ & 1 \\
\hline & $4-2-1$ & 1 \\
\hline
\end{tabular}


$97.1 \%$ on the left major row (Tables 2 and 3 ). The authors accordingly analyzed the bilaterally asymmetrical dention of the replacement pattern.

The existent rate of the tooth germs was expressed as the number of tooth germs per functioning tooth in each row. The rate becomes 0.4 in the case where there are four tooth germs in the left major row, and 1.0 in the case where there are four teeth in the right major row. The mean of the existent rate of the tooth germs was estimated according to the Student's $t$-distribution (95\% confidence, Table 4$)$. There was a significant difference in the mean of the existent rate in each row according to the Student's $t$-test or Aspin-Welch's $t$-test, which was given at the $95 \%$ confidence level. The existent rate of the tooth germs $(0.79 \pm 0.07)$ in the right major row bearing four teeth was higher than that $(0.68 \pm 0.05)$ in the left major row bearing five teeth. Therefore, it is concluded that a tooth row bearing more teeth does not replace teeth more frequently for the major rows of the bilaterally asymmetrical dentition. The existent rate of the tooth germs in the minor row was very low in spite of the small number of teeth. The

Table 4. The existent rate, the number of tooth germs per functioning tooth, in each row.

\begin{tabular}{cc}
\hline Tooth row & mean (95\% confidence interval) \\
\hline Right arch & \\
Major row & $0.79 \pm 0.07$ \\
Minor row & $0.27 \pm 0.09$ \\
Left arch & \\
Major row & $0.68 \pm 0.05$ \\
Minor row & $0.15 \pm 0.08$ \\
\hline
\end{tabular}

minor row seems to replace the teeth less frequently, because their teeth are not more functional, than the major row. The correlation coefficients were calculated between the numbers of the tooth germs in each row. The correlation coefficients showed that the number of the tooth germs in each row does not correlate each other. Therefore, it is concluded that each row replaces the teeth, independently.

\section{Acknowledgement}

The authors wish to express their thanks to Professor Kuhei Furuhashi for his suggestions throughout their study. This study was supported in part by Grant-in-aid (no. 58771265) for Scientific Research from the Ministry of Education of Japan, 1983.

\section{References}

1) Evans, H. E. and Deubler, E. E. Jr.: Pharyngeal tooth replacement in Semotilus stromaculatus and Clinostomus elongatus, two species of cyprinid fishes. Copeia 1955: 31$34,1955$.

2) Nakajima, T.: The development and replacement pattern of pharyngeal dentition in Japanese cyprinid fish, Gnathopogon coerulescens. ibid. 1979: 22-28, 1979.

3) Nkajima, T.: A comparative study of the development of the pharyngeal dentition in cyprinoid fishes. $\mathrm{Ph} \mathrm{D}$ Thesis Kyoto Univ. 1982, (in Japanese).

4) Nakajima, T., Sugito, M., Nakahara, M. and Ozaki, M.: An analysis of the pattern of tooth replacement in cyprinid fish, Rhodeus ocellatus ocellatus. Jpn. J. Oral Biol. 23: 893-895, 1981.

5) Nakamura, M.: Gyprinid fish in Japan. Spec. Publ. Reas. Inst. Natr. Reso., No. 4, 1969, (in Japanese). 